\title{
Assessment of Pathogenic Variation against Pitch Canker Pathogen, Fusarium circinatum in Pinus thunbergii and Responses of Natural Selection Pinus $\times$ rigitaeda to Branch Inoculation in a Seed Orchard
}

\author{
Kwan-Soo Woo $^{1 *}$, Jun-Hyuck Yoon ${ }^{2}$, Sang-Urk Han ${ }^{1}$ and Chang-Soo Kim ${ }^{1}$ \\ ${ }^{1}$ Department of Forest Resources Development, Korea Forest Research Institute, Suwon 441-847, Korea \\ ${ }^{2}$ Southern Forest Research Center, Korea Forest Research Institute, Jinju 660-300, Korea
}

(Received on April 12, 2010; Accepted on September 18, 2010)

\begin{abstract}
A half-sib family of two 4-year-old seedlings of Pinus $\times$ rigitaeda was inoculated with each of 20 Pinus thunbergii isolates of Fusarium circinatum (syn. Fusarium subglutinans f. sp. pini) from two pitch canker damaged sites in Jeju Island, South Korea. Initial symptoms of needle damages were visible on most of the seedlings at 18 days after inoculation. The 20 tested isolates were not significantly different in virulence, based on lesion lengths at the site of inoculation $(P=0.217)$. The most virulent isolate FT-7 showed the longest lesion length. Some seedlings began to die $\mathbf{4 6}$ days after inoculation. All seedlings were dead by 68 days after inoculation except two seedlings inoculated with each of isolates FS2 and FS-13, respectively. Using the FT-7, 38-year-old 11 $P$. $\times$ rigitaeda trees, which were survived from a seed orchard severely damaged by pitch canker, were inoculated on branches in the seed orchard in Jeju Island to assess differences in susceptibility to pitch canker. The 11 trees differed significantly $(P<0.001)$ in susceptibility to $F$. circinatum based on average lesion lengths measured 56 days after inoculation. It is possible that induced resistance contributed to their capacity to limit lesion development. The susceptibility of natural selection $P$. $\times$ rigitaeda trees are more likely affected by interaction with $F$. circinatum rather than environmental conditions.
\end{abstract}

Keywords : Fusarium circinatum, Natural selection, Pinus thunbergii, Pinus $\times$ rigitaeda, Susceptibility

Pitch canker is a serious disease of pines, which is caused by the fungus Fusarium circinatum Nirenberg \& O'Donnell (syn. Fusarium subglutinans f. sp. pini; telemorph: Giberella circinatum Nirenberg \& O'Donnell) distributed in different parts of the world (Correll et al., 1991; Dwinell et al., 1985; Gordon et al., 2001; Nirenberg and O'Donnell, 1998). Advanced symptoms of the disease result in crown dieback

\footnotetext{
*Corresponding author.

Phone) +82-31-290-1106, FAX) +82-31-292-8468

E-mail)woo9431@forest.go.kr
}

and resinous cankers on branches and main stems (Storer et al. 2002). Pitch canker was first reported in 1946 on Pinus virginiana in North Carolina, USA (Hepting and Roth, 1946), and it later appeared on Pinus elliottii in Florida, Pinus taeda in Mississippi, and on Pinus radiata in California where it has caused a significant epidemic in its native range (Dwinell and Phelps, 1977; Gordon et al., 2001; Storer et al., 1997). The pathogen is also found in Japan (Kobayashi and Muramoto, 1989), South Africa (Viljoen et al., 1994), Mexico (Guerra-Santos, 1999), South Korea (Lee et al., 2000), Chile (Wingfield et al., 2002), Spain (Landeras et al., 2005), and was recently reported from Italy (Carlucci et al., 2007).

In South Korea, pitch canker was first noticed as a cause of branch dieback on the exotic species Pinus rigida Mill. in Incheon city in the mid-1990s. Pitch canker may be alleged to have introduced into South Korea through two routes: one from the USA to Incheon city and the other from Japan to Jeju Island. The disease has caused a serious damage mostly on three-needle pines, $P$. rigida and $P$. $\times$ rigitaeda in the southwestern part of the Korean peninsula and Jeju Island. Most infections appear to result from weather-related wounds from wind that serves as entry points of micro- or macro-conidia.

The seed orchards of $P$. rigida and $P . \times$ rigitaeda in Jeju Island have been damaged by pitch canker for about ten years perhaps because of warm temperature and geographic location near to Japan where the disease has been established since the late 1980s (Kobayashi and Muramoto, 1989; Woo et al., 2005). Recently, the disease occurred more often on sapling stands of a native two-needle pine $P$. thunbergii on the roadside and a golf course in Jeju Island. The isolates of $F$. circinatum obtained from different pine hosts, for example, $P$. nigra, P. pinaster, $P$. sylvestris, and $P$. radiata in Spain (Perez-Sierra et al., 2007) and P. taeda, and P. elliottii in USA (Hodge and Dvorak, 2007), were tested for virulence. However, virulence to $P$. thunbergii isolates of $F$. circinatum has not been reported previously.

Phenotypes of relatively resistant pines are characterized by a reduced rate of lesion development and thus less 
dieback, compared to more susceptible pine trees. Pitch canker resistant trees have been screened in a greenhouse environment (Gordon et al., 1998a and b; Hodge and Dvorak, 2000) even though testing on big trees and natural selection trees would be more desirable. Natural selection trees of $P$. $\times$ rigitaeda seed orchard provide us an opportunity to evaluate their resistance. The objectives in this study were to 1) assess variation in virulence in isolates of $F$. circinatum from $P$. thunbergii and 2) test for differences in susceptibility to pitch canker in $P$. $\times$ rigitaeda.

\section{Materials and Methods}

Pathogenicity test of $\boldsymbol{F}$. circinatum from $\boldsymbol{P}$. thunbergii. Twenty isolates of $F$. circinatum tested in this study were obtained from each of 20 P. thunbergii individuals damaged by the pitch canker from two sites (site FT: 7 trees along the roadside; site FS: 13 trees within a golf course) in Jeju Island. Site FT is located in Saekdaldong, Seogwipo city, and site FS is in Oradong, Jeju city, about 10 kilometers away from the site FT as the crow flies. Each isolate was sub-cultured as a single spore on potato dextrose agar (PDA) at $24 \pm 1^{\circ} \mathrm{C}$ for 5 days. Each of the 20 isolates were used for inoculations on July 10, 2008 on the main stems of a half-sib family of two 4-year-old seedlings of Pinus $\times$ rigitaeda by removing an area of bark approximately $1 \mathrm{~cm}$ long and $0.5 \mathrm{~cm}$ wide. An equal size plug ( $5 \mathrm{~mm}$ diameter) of PDA that was fully colonized by $F$. circinatum was placed into each wound with the mycelium facing down, and the wounds were sealed with parafilm to prevent contamination and drying of the inoculum. Control seedlings were also wounded and inoculated with sterile water. Visual damages, either dehydration or discoloration of needles, were examined weekly on seedlings inoculated with the isolates for 68 days. F. circinatum was re-isolated from symptomatic seedlings to confirm infection by the pathogen.

Lesion length. Pathogenic variation of the isolates was determined based on the lengths of lesions developing on main stem subjected to the mechanical inoculations. The length of lesion was characterized by brown discoloration of resin soaked xylem. To measure lesion length on main stem, inoculated stems were cut at the bottom, bark was removed from the inoculation site to up- and downwards until normal appearing wood was revealed, and lesion length was measured to the nearest $\mathrm{mm}$. The isolate showing the longest mean lesion length was chosen for subsequent branch inoculations of trees survived from a seed orchard severely damaged ( $98 \%$ mortality) by pitch canker.

Branch inoculations. Eleven natural selection Pinus $\times$ rigitaeda trees that were 38 years old in the Sanghyo Seed
Table 1. Details of individual trees of natural selection $P . \times$ rigitaeda

\begin{tabular}{|c|c|c|c|c|c|}
\hline \multirow{3}{*}{$\begin{array}{l}\text { Trees } \\
\text { isolates }\end{array}$} & \multicolumn{5}{|c|}{ Characteristics } \\
\hline & \multirow{2}{*}{$\begin{array}{l}\text { Height } \\
\text { (m) }\end{array}$} & \multirow{2}{*}{$\begin{array}{l}\mathrm{DBH}^{\mathrm{a}} \\
(\mathrm{cm})\end{array}$} & \multirow{2}{*}{$\begin{array}{l}\text { Crown height } \\
\text { (m) }\end{array}$} & \multicolumn{2}{|c|}{ Crown width $(\mathrm{cm})$} \\
\hline & & & & Major & Minor \\
\hline R4 & 9.4 & 35.5 & 6.5 & 740 & 630 \\
\hline R7 & 8.6 & 45.8 & 6.0 & 860 & 760 \\
\hline $\mathrm{R} 8$ & 8.8 & 46.5 & 4.9 & 820 & 690 \\
\hline R11 & 10.2 & 44.8 & 6.4 & 740 & 660 \\
\hline $\mathrm{R} 12$ & 10.2 & 51.4 & 6.8 & 930 & 830 \\
\hline $\mathrm{R} 16$ & 10.9 & 58.0 & 8.0 & 990 & 830 \\
\hline R17 & 11.3 & 44.5 & 8.0 & 860 & 830 \\
\hline R19 & 7.7 & 39.0 & 4.8 & 910 & 680 \\
\hline $\mathrm{R} 25$ & 10.5 & 46.8 & 7.4 & 930 & 830 \\
\hline $\mathrm{R} 26$ & 10.5 & 39.1 & 7.5 & 890 & 880 \\
\hline $\mathrm{R} 27$ & 9.3 & 42.0 & 6.6 & 810 & 790 \\
\hline
\end{tabular}

${ }^{\mathrm{a}}$ Diameter at breast height

Orchard in Jeju Island (hereafter referred to as the Jeju Sanghyo $P . \times$ rigitaeda Seed Orchard) were used for branch inoculations. All trees had no symptoms of natural infections by $F$. circinatum, nor had other disease and insect problems. The Jeju Sanghyo $P \times$ rigitaeda Seed Orchard was established on 10 hectares of area in 1972 to provide superior seeds of Pinus $\times$ rigitaeda nationwide, but since the first outbreak of pitch canker in the late 1990s (Woo et al. 2005), most of the trees were killed by pitch canker, and consecutive outbreaks of the disease have left only about 50 out of 4,000 trees as of August, 2008. All The details of individual trees are in Table 1. Cultures of selected isolate (FT-7) were grown on PDA at $24 \pm 1^{\circ} \mathrm{C}$ for 5 days. Twenty inoculations on each tree were performed on similar diameters branches (range: $5.2-11.2 \mathrm{~mm}$ ). Inoculations were equally placed on the southern and northern side of the crown, from August 26-28, 2008 by the same inoculation method as mentioned earlier. Control inoculations of sterile water agar plugs were conducted on 10 branches per tree, 5 branches in each of the southern and northern side of the crown. Branches were collected 56 days following inoculation, and the lesion at the site of inoculation was measured. Average lesion lengths were calculated for each tree.

Data analysis. Data on lesion length of Pinus $\times$ rigitaeda seedlings inoculated with 20 isolates and those of 11 natural selection Pinus $\times$ rigitaeda trees were analyzed by analysis of variance (ANOVA) using SAS-PROC GLM (general linear model) statistical package and type III sums of squares (SAS Institute Inc. 1989). A Pearson correlation analysis used natural selection individual tree data. 


\section{Results and Discussion}

Pathogenicity test. We confirmed that 20 isolates obtained from $P$. thunbergii in two sites were the pitch canker fungus based on morphology and molecular techniques (data not shown). The isolates were used for inoculating seedlings of Pinus $\times$ rigitaeda, which is one of the most susceptible three-needle pines in Korea, and in this study, we found that the initial symptom of needle damage was visible on most of the seedlings inoculated with FT isolates at 18 days after inoculation, but slightly less on the seedlings inoculated with FS isolates (Figs. 1a, 1b). Twenty isolates of F. circinatum were not significantly different in virulence, based on lesion lengths at the site of inoculation $(p=0.217)$ (Fig. 2). The mean lesion length on seedlings inoculated with isolate FS-8 was the shortest $(12.8 \mathrm{~mm})$ and that on seedlings inoculated with isolate FT-7 was the longest (44.9 $\mathrm{mm})$, which was $82 \%$ greater than total mean $(24.7 \pm 9.2$ $\mathrm{mm}$ ).

A few studies on variation in virulence of the pitch canker fungus have been reported (Gordon et al., 2001; Hodge and Dvorak, 2007; Perez-Sierra et al., 2007), and the variation could result from introduction of new strains, recombination by out-crossing, or mutation. Virulence of seven isolates of $F$. circinatum from seeds, seedlings, and mature trees of four pine species has been evaluated in northern Spain, and all isolates were pathogenic and the virulence was significantly different within each species (Perez-Sierra et al., 2007).

Fusarium circinatum populations in southeastern United States, Mexico and South Africa were genetically varied
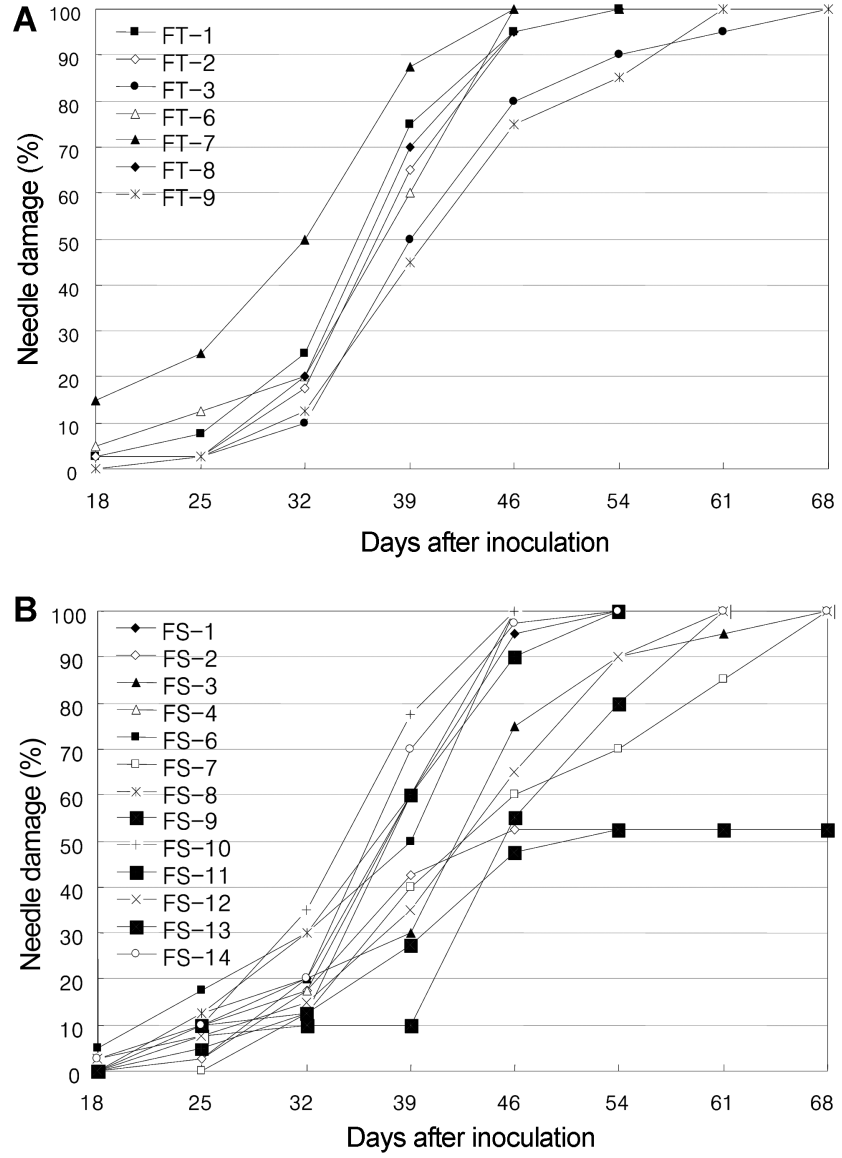

Fig. 1. Percentage of needle damages (either dehydration or discoloration of needles) of two 4-year-old seedlings of Pinus $\times$ rigitaeda inoculated with each of 7 isolates of $F$. circinatum from site FT (A) and 13 isolates from site FS (B) for 68 days.

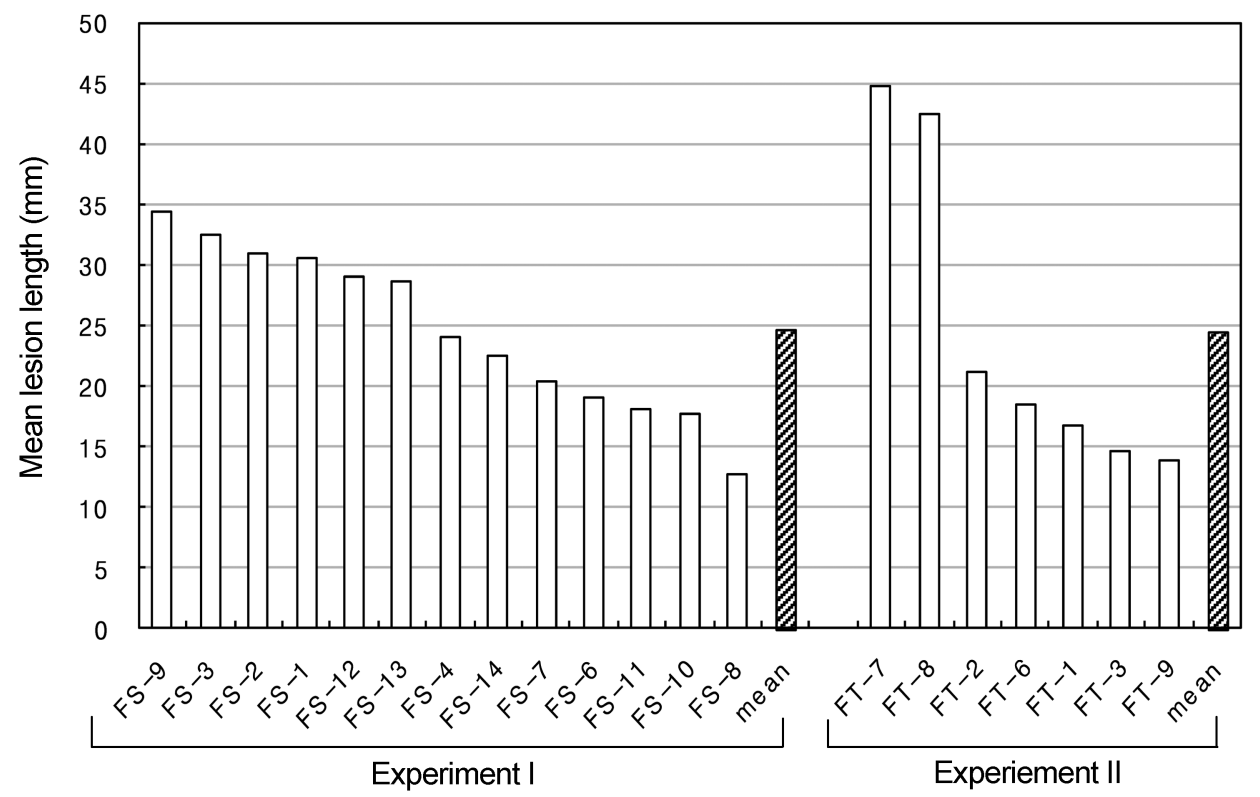

Fig. 2. Variation in susceptibility of Pinus $\times$ rigitaeda seedlings against 20 isolates of $F$. circinatum $(P=0.217)$. 
and the variation may be resulted from mutation (Wikler and Gordon, 2000). However, there is no specific evidence of sexual reproduction in Japan and California (Wingfield et al., 2008). Since the pitch canker pathogen is supposed to be introduced from Japan, no sexual reproduction is evident in South Korea.

The time period from inoculation to mortality varies depending on species and ages of host trees and virulence of the pathogen. Seven to eight-month-old seedlings of $P$. nigra were all dead 29 days after inoculation with Spanish isolates of $F$. circinatum, but those of Pinus pinaster and $P$. sylvestris died 49 and 56 days after inoculation, respectively (Perez-Sierra et al., 2007). In this study, some seedlings began to die 46 days after inoculation. All but one seedling inoculated with each of isolates FS-2 and FS-13 were dead by 68 days after inoculation (Figs. 1b, 3), indicating that all isolates tested were highly pathogenic to the $P$. $\times$ rigitaeda, with $95 \%$ mortality. No external symptoms of disease development were observed on the control seedlings by the end of the experiment (Fig. 3).

Non-native three-needle pines ( $P$. rigida and $P . \times$ rigitaeda) are the principal hosts to pitch canker in South Korea. However, native two-needle pine, $P$. thunbergii, is also being damaged by the disease especially in Jeju Island. In a previous test, we found that the mortality of three-yearold seedlings of $P$. $\times$ rigitaeda inoculated with an isolate from $P$. rigida in Baekryeong Island, Kyeonggi province, South Korea was zero (Kim et al., 2008). However, in this study, most of the seedlings of $P$. $\times$ rigitaeda had died by the fungus isolated from $P$. thunbergii. In another study, the virulence of $F$. circinatum obtained from the seed of $P$. thunbergii in Jeju Island was very low, with only $5 \%$ mortality (Woo et al., 2005), suggesting that the variation of the virulence of the pathogen differs by the origin of the fungus and individual hosts.

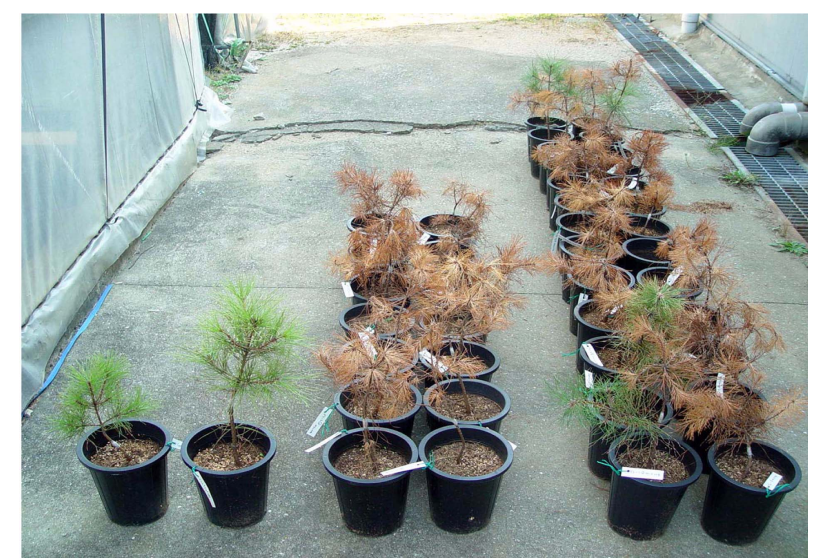

Fig. 3. Comparisons of disease symptoms on Pinus $\times$ rigitaeda seedlings at 68 days after inoculation with 20 isolates of Fusarium circinatum and control.
Pitch canker is significantly more severe, and is spreading faster in managed landscape types than in the wild land stands (Wikler et al., 2003). In the current study, the distance between the two sites is only about 10 kilometers, but we observed more damaged trees by the pitch canker in the site FS than in the site FT. The site FS is a golf course, where trees are more intensively managed than those at site FT, which is less disturbed by human activities. Also, micro-environmental variation between the two sites could affect the success of the pathogen in colonizing its host. Among the FT isolates tested in this study, FT-7, which was the most virulent isolate, was selected as an inoculum of the future screening tests for breeding for resistance to the pitch canker.

Branch inoculations. A number of previous studies have been performed to clarify differences in the susceptibility of Pinus spp. either using stem inoculations (Enebak and Stanosz, 2003; Matheson et al., 2006; Porter et al., 2009; Viljoen et al., 1997) or branch inoculations (Gordon et al., 1998a and b; Sakamoto and Gordon, 2006). It seems likely that the susceptibility of seedlings could be assessed by either stem inoculations or branch inoculations, but for larger trees in the field, branch inoculations would allow for the speedy screening of disease resistant individuals. Branch inoculation results on larger trees were closely correlated with those from stem inoculations (Roux et al., 2007).

Relatively resistant trees show a reduced rate of lesion

Table 2. Mean and standard deviations of lesion length by individual trees, with the number of branches inoculated in each tree and a multiple range summary based on Duncan's multiple range tests

\begin{tabular}{cccc}
\hline $\begin{array}{c}\text { Trees } \\
\text { isolates }\end{array}$ & $\begin{array}{c}\text { Number of } \\
\text { branches }^{\mathrm{a}}\end{array}$ & $\begin{array}{c}\text { Lesion length }(\mathrm{mm})^{\mathrm{b}} \\
(\text { mean } \pm \text { SD) }\end{array}$ & $\begin{array}{c}\text { Multiple range } \\
\text { summary }^{\mathrm{c}}\end{array}$ \\
\hline R16 & 20 & $51.3 \pm 11.4$ & $\mathrm{~A}$ \\
R8 & 20 & $50.9 \pm 9.8$ & $\mathrm{~A}$ \\
R12 & 20 & $49.2 \pm 13.1$ & $\mathrm{~A}$ \\
R19 & 20 & $48.7 \pm 9.4$ & $\mathrm{~A}$ \\
R4 & 20 & $48.3 \pm 8.7$ & $\mathrm{~A}$ \\
R11 & 20 & $40.3 \pm 9.3$ & $\mathrm{~B}$ \\
R26 & 20 & $39.4 \pm 9.2$ & $\mathrm{~B}$ \\
R27 & 20 & $38.9 \pm 12.6$ & $\mathrm{~B}$ \\
R25 & 20 & $36.9 \pm 4.0$ & $\mathrm{~B}$ \\
R17 & 20 & $29.5 \pm 8.0$ & $\mathrm{C}$ \\
R7 & 20 & $28.7 \pm 4.4$ & C \\
\hline
\end{tabular}

${ }^{a}$ This includes total number of branches inoculated with $F$. circinatum per tree.

${ }^{\mathrm{b}}$ Lesion lengths were measured at the wound site 56 days after inoculation.

${ }^{\mathrm{c}}$ One or more common letters indicate that means are not significantly different at $5 \%$ level. 
development compared to more susceptible one. Resistant trees do not show any girdling lesions, and they sustain less branch dieback than more susceptible individuals. There was a statistically significant difference $(\mathrm{p}<0.001)$ among 11 natural selection trees for susceptibility to $F$. circinatum based on average lesion lengths measured 56 days after inoculation (Table 2). Tree R16 showed the longest lesion $(51.3 \pm 11.4 \mathrm{~mm})$, and tree R7 was the shortest $(28.7 \pm 4.4$ $\mathrm{mm})$. The multiple range summary indicates that both $\mathrm{R} 17$ $(29.5 \pm 8.0 \mathrm{~mm})$ and R7 trees have significantly shorter lesions than the rest of trees (Table 2). It also indicates that trees R11, R25, R26, and R27 have significantly shorter lesions than trees R4, R8, R12, R16, and R19. There was no significant difference $(P=0.53)$ between the southern and northern branches for mean lesion length (Fig. 4). However, the difference was significant for interaction between trees and the direction $(P<0.01)$. We re-isolated the fungus from inoculated branches of all trees tested.

The height of 11 trees was positively correlated with the crown height and the minor crown width $(\mathrm{r}=0.925 ; P<$ 0.001 and $\mathrm{r}=0.620 ; P<0.05$, respectively). The minor crown width was also correlated with the major crown width and the crown height $(\mathrm{r}=0.698 ; P<0.05$ and $\mathrm{r}=$ $0.717 ; P<0.05$, respectively). However, lesion length was not correlated with any of the morphological measurements of the trees.

Susceptibility is more likely affected by the interaction between pathogen and host rather than environmental (ambient) conditions, especially for resistant stocks. In the recent study, 2 of 6 pine species or hybrid seedlings, $P$. echinata and $P$. virginiana, were the most susceptible to infection by Korean isolate of $F$. circinatum (Kim et al., 2008). However, some studies provided solid evidence on the seasonal and weather-related variations in levels of

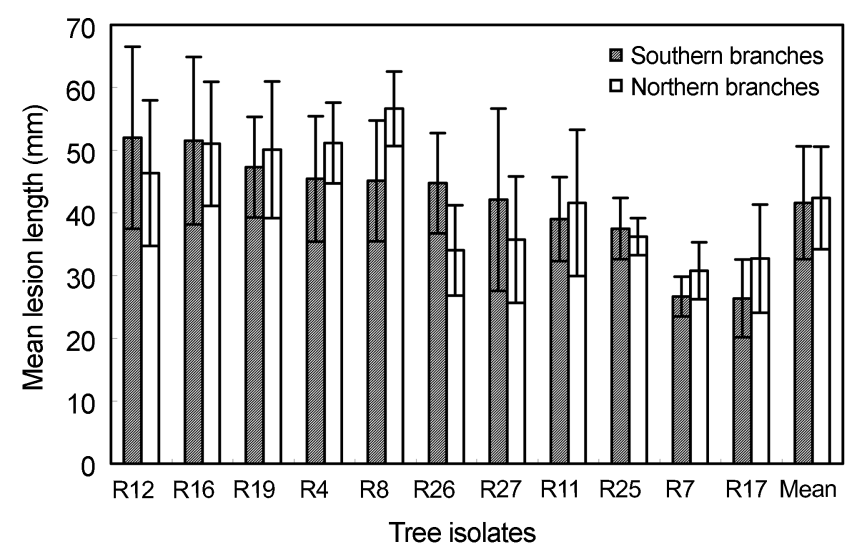

Fig. 4. Variation in susceptibility to F. circinatum infection caused by the inoculations of 10 branches on each of the southern and northern sides of trees. Error bars correspond to the standard deviation of the mean. spore deposition rates of $F$. circinatum (Garbelotto et al., 2008; Schweigkofler et al., 2004).

Temperature is one of the most important factors influencing the distribution of pitch canker. Inman et al. (2008) suggested that if low temperatures extend the time required for growth and spore germination, infection frequency by pitch canker would be reduced. The risk of pitch canker establishment was predicted using the process-based distribution program based on a number of climatic variables (Ganley et al., 2009). Low elevation sources of the seedlings of $P$. patula and $P$. tecunumanii showed significantly higher resistance to $F$. circinatum than those from high elevation (Hodge and Dvorak, 2007). Pitch canker outbreaks in the Southeast United States have been related with hurricanes (Dwinell et al., 1985). Also, high levels of nutrients, both in pine needles and soils, are associated with increasing severity of the pitch canker disease (Lopez-Zamora et al., 2007). Therefore, environmental factors are known to contribute to pitch canker disease in many aspects. In the current study, relatively little is known about not only the infection process and natural dispersal of $F$. circinatum, but also the role of a sexual stage of the fungus, Gibberella circinata, for infection of host species. Further studies are needed to clarify these issues.

Pitch canker is a non-native pathogen, which is highly aggressive to native stands and/or in our case, seed orchards because there was no long-period selection for compatible interactions between the parasite and their host. The effect of natural selection on the susceptibility of host population is that the more resistant host genotypes are likely to leave the more progeny, resulting in diminishing damage by an exotic pathogen. However, Aegerter and Gordon (2006) suggested that resistance to pitch canker that is expressed in mature trees is not operative in emerging seedlings. Therefore, natural-regeneration seedlings are challenged to escape infection by $F$. circinatum until the resistance is operative. Relatively resistant trees identified by branch inoculation in this study should have less damage than more susceptible trees. Because all eleven trees have been in the presence of pitch canker for many years, it is likely they have been infected, even though symptoms may never have developed. Consequently, it is possible that induced resistance contributed to their capacity to limit lesion development. These trees are very useful to increase the number of resistant phenotypes to cope with the pitch canker epidemic in the future. The evidence of resistance to the pitch canker pathogen in native stands of Monterey pine has been confirmed previously (Storer et al., 1999).

$F$. circinatum can grow into host tissues before it is restricted completely even though host trees appear to be phenotypically resistant to the fungus (Aegerter and Gordon, 2006; Kim et al., 2008). In a previous test (Kim et al., 
2008), we suggested that the fungus was re-isolated from resistant host tissues without necessarily resulting in lesion development. In the current branch inoculations, 56 days after inoculation, we observed both infected and uninfected branches which are all artificially inoculated and are right next to each other within a single genotype even though the frequency was very low. Additional studies are needed to clarify and describe resistance mechanisms, especially those that contain fungal growth.

\section{Conclusions}

Initial symptoms of needle damages were observed at about 2 weeks after inoculation with isolates of Fusarium circinatum in Pinus thunbergii. The virulence of 20 tested isolates was not significantly different, but some isolates such as FT-7 and FT-8 showed much higher virulence than others. Eleven $P . \times$ rigitaeda tree isolates, which were survived from a seed orchard severely damaged by pitch canker, differed significantly in susceptibility to $F$. circinatum measured 56 days after inoculation. It is possible that induced resistance contributed to their capacity to limit lesion development, and the susceptibility of $P$. $\times$ rigitaeda trees are more likely affected by interaction with $F$. circinatum rather than environmental factors.

\section{Acknowledgments}

We would like to appreciate Dr. Bryce Richardson, research geneticist, USDA Forest Service, RMRS, Provo, Utah, USA, in reviewing this manuscript.

\section{References}

Aegerter, B. J. and Gordon, T. R. 2006. Rates of pitch canker induced seedling mortality among Pinus radiate families varying in levels of genetic resistance to Gibberella circinata (anamorph Fusarium circinatum). For. Ecol. and Manage. 235:14-17.

Carlucci, A., Colatruglio, L. and Frisullo, S. 2007. First report of pitch canker caused by Fusarium circinatum on Pinus halepensis and P. pinea in Apulia (Southern Italy). Plant Dis. 91:1683.

Correll, J. C., Gordon, T. R., McCain, A. H., Fox, J. W., Koehler, C. S., Wood D. L. and Schultz, M. E. 1991. Pitch canker disease in California: pathogenicity, distribution, and canker development on Monterey pine (Pinus radiata). Plant Dis. 75:676-682.

Dwinell, L. D., Barrows-Broaddus, J. B. and Kuhlman, E. G. 1985. Pitch canker: a disease complex of southern pines. Plant Dis. 69:270-276.

Dwinell, L. D. and Phelps, W. R. 1977. Pitch canker of slash pines in Florida. J. For. 75:488-489.
Enebak, S. A. and Stanosz, G. R. 2003. Responses of conifer species of the Great Lakes region of North America to inoculation with the pitch canker pathogen Fusarium circinatum. For. Pathol. 33:333-338.

Ganley, R. J., Watt, M. S., Manning, L. and Iturritxa E. 2009. A global climatic risk assessment of pitch canker disease. Can. J. For. Res. 39:2246-2256.

Garbelotto, M., Smith, T. and Schweigkofler, W. 2008. Variation in rates of spore deposition of Fusarium circinatum, the causal agent of pine pitch canker, over a 12-month-period at two locations in Northern California. Phytopathology 98:137-143.

Gordon, T. R., Okamoto, D., Storer, A. J. and Wood, D. L. 1998a. Susceptibility of five landscape pines to pitch canker disease, caused by Fusarium subglutinans f. sp. pini. HortScience 33:868-871.

Gordon, T. R., Storer, A. J. and Wood. D. L. 2001. The pitch canker epidemic in California. Plant Dis. 85:1128-1139.

Gordon, T. R., Wikler, K. R., Clark, S. L., Okamoto, D., Storer, A. J. and Bonello, P. 1998b. Resistance to pitch canker disease, caused by Fusarium subglutinans f. sp. pini. in Monterey pine (Pinus radiata). Plant Pathol. 47:706-711.

Guerra-Santos, J. J. 1999. Pitch canker in Monterey pine in Mexico. In: Current and Potential Impacts of Pitch Canker in Radiata Pine. Proceedings of IMPACT Monterey Workshop, Monterey Calif., 30 November-3 December 1998. Edited by M.E. Devey, A.C. Matheson, and T.R. Gordon. CSIRO, Australia, 58-61.

Hepting, G. H. and Roth, E. R. 1946. Pitch canker, a new disease of southern pines. J. For 44:742-744.

Hodge, G. R. and Dvorak, W. S. 2000. Differential response of central American and Mexican pine species and Pinus radiata to infection by the pitch canker fungus. New For. 19:241-258.

Hodge, G. R. and Dvorak, W. S. 2007. Variation in pitch canker resistance among provenances of Pinus patula and Pinus tecunumanii from Mexico and central America. New For. 33:193-206.

Inman, A. R., Kirkpatrick, S. C., Gordon, T. R. and Shaw, D. V. 2008. Limiting effects of low temperature on growth and spore germination in Gibberella circinata, the cause of pitch canker in pine species. Plant Dis. 92:542-545.

Kim, Y. S., Woo, K. S., Koo, Y. B. and Yeo, J. K. 2008. Variation in susceptibility of six pine species and hybrids to pitch canker caused by Fusarium circinatum. For. Path. 10:1-10.

Kobayashi, T. and Muramoto, M. 1989. Pitch canker of Pinus luchuensis, a new disease in Japanese forest. Forest Pests 38:169-173.

Landeras, E., Garcia, P., Fernandez, Y., Brana, M., FernandezAlonso, O., Mendez-Lodos, S., Perez-Sierra, A., Leon, M., Abad-Campos, P., Berbegal, M., Beltran, R., Garcia-jimenez, J. and Armengol, J. 2005. Outbreak of pitch canker caused by Fusarium circinatum on Pinus spp. in Northern Spain. Plant Dis. 89:1015.

Lee, J. K., Lee, S. H., Yang, S. I. and Lee, Y. W. 2000. First report of pitch canker disease on Pinus rigida in Korea. Plant Pathol. J. 16:52-54.

Lopez-Zamora, I., Bliss, C., Jokela, E. J., Comerford, N. B., 
Grunwald, S., Bamard, E. L. and Vasquez, G. M. 2007. Spatial relationships between nitrogen status and pitch canker disease in slash pine planted adjacent to a poultry operation. Environ. Pollut. 147:101-111.

Matheson, A. C., Devey, M. E., Gordon, T. L., Werner, W., Vogler, D. R., Balocchi, C. and Carson, M. J. 2006. Heritability of response to inoculation by pine pitch canker of seedlings of radiata pine. Austral. For. 62:101-106.

Nirenberg, H. I. and O'Donnell, K. 1998. New Fusarium species and combinations within the Gibberella fujikuroi complex. Mycologia 90:434-458.

Perez-sierra, A., Landeras, E., Leon, M., Berbegal, M., GarciaJimenez, J. and Armengol, J. 2007. Characterization of Fusarium circinatum from Pinus spp. in northern Spain. Mycol. Res. 111:832-839.

Porter, B., Wingfield, M. J. and Coutinho, T. A. 2009. Susceptibility of South African native conifers to the pitch canker pathogen, Fusarium circinatum. S. Afr. J. Bot. 75:380-382.

Roux, J., Eisenberg, B., Kanzler, A., Nel, A., Coetzee, V., Kietzka, E. and Wingfield, M. J. 2007. Testing of selected South African Pinus hybrids and families for tolerance to the pitch canker pathogen, Fusarium circinatum. New For. 33:09-123.

Sakamoto, J. M. and Gordon, T. R. 2006. Factors influencing infection of mechanical wounds by Fusarium circinatum on Monterey pines (Pinus radiata). Plant Pathol. 55:130-136.

SAS Institute Inc. 1989. SAS/STAT user's guide, version $6.4^{\text {th }}$ ed. SAS Institute Inc., Cary, N.C.

Schweigkofler, W., O'Donnell, K. and Garbelotto, M. 2004. Detection and quantification of airborne conidia of Fusarium circinatum, the causal agent of pine pitch canker, from two California sites by using a real-time PCR approach combined with a simple spore trapping method. Appl. Environ. Microbiol. 70:3512-3520.

Storer, A. J., Bonello, P., Gordon, T. R. and Wood, D. L. 1999. Evidence of resistance to the pitch canker pathogen (Fusarium subglutinans f. sp. pini) in native stands of Monterey pine (Pinus radiata). For. Sci. 45:500-505.

Storer, A. J., Gordon, T. R., Wood, D. L. and Bonello, P. 1997. Current and future impacts of pitch canker disease of pines. $J$. For. 95:21-26.

Storer, A. J., Wood, D. L. and Gordon, T. R. 2002. The epidemiology of pitch canker of Monterey pine in California. For. Sci. 48:694-700.

Viljoen, A., Wingfield, M. J. and Marasas, W. F. O. 1994. First report of Fusarium subglutinans $\mathrm{f}$. sp. pini on pine seedlings in South Africa. Plant Dis. 78:309-312.

Viljoen, A., Wingfield, M. J., Marasas, W. F. O. and Coutinho, T. A. 1997. Pitch canker of pines: a contemporary review. S. Afr. J. Sci. 93:411-413.

Wikler, K. and Gordon. T. R. 2000. An initial assessment of genetic relationships among population of Fusarium circinatum in different parts of the world. Can. J. Bot. 78:709-717.

Wikler, K., Storer, A. J., Newman, W., Gordon, T. R. and Wood, D. L. 2003. The dynamics of an introduced pathogen in a native Monterey pine(Pinus radiata) forest. For. Ecol. and Manage. 179:209-221.

Wingfield, M. J., Hammerbacher, A., Ganley, R. J., Steenkamp, E. T., Gordon, T. R., Wingfield, B. D. and Coutinho, T. A. 2008. Pitch canker caused by Fusarium circinatum - a growing threat to pine plantations and forests worldwide. Austral. Plant Pathol. 37:319-334.

Wingfield M. J., Jacobs, A., Coutinho, T. A., Ahumada R. and Wingfield, B. D. 2002. First report of the pitch canker fungus, Fusarium circinatum, on pines in Chile. Plant Pathol. 51:397.

Woo, K. S., Kim, Y. J., Kim, T. S. and Lee, S. K. 2005. Selection of virulent isolates of Fusarium circinatum and investigation of pitch canker severity of Pinus rigida and $P$. rigida $\times P$. taeda seed orchards in Jeju Island. Jour. Korean For. Soc. 94:402-409. 